\title{
Antropologia visual, práticas antigas e novas perspectivas de investigação
}

\author{
José da Silva Ribeiro \\ Coordenador do Laboratório de Antropologia Visual \\ - Universidade Aberta de Lisboa
}

RESUMO: A antropologia visual nasceu em meados do século XIX com a "era da reprodutibilidade técnica" e da expansão industrial. Como se reformula hoje, na era da globalização e da transformação digital, essa disciplina ou convergência disciplinar? Voltada inicialmente para a documentação e preservação de práticas culturais ameaçadas, a antropologia de urgência, como se transformou ao longo do tempo em formas narrativas visuais, sonoras, audiovisuais e, mais recentemente, digitais? Orientada em primeiros passos para alimentar e enriquecer as coleçóes dos museus, como passa hoje por meio de múltiplas formas e suportes para o espaço público à procura de novos espectadores/atores (ou públicos)? Inicialmente instrumentação que pareceria garantir a objetividade, atribuindo-se-lhe o estatuto de tecnologia de pesquisa ou mesmo de auxiliar de pesquisa, como se confrontou com novos paradigmas epistemológicos ou se antecipou a eles? Voltada sobretudo para o registo das técnicas materiais e rituais e depois para as palavras e as sonoridades, como se orienta hoje no âmbito de novos objetos de estudo como a antropologia da arte, a antropologia do design, a cultura visual em contextos de processos acelerados de transformação social e cultural? Acrescentamos ainda mais duas perguntas às inquietações que nos fazem refletir sobre essa temática: como se repensa atualmente a antropologia visual no âmbito da antropologia? O que fazer com a antropologia visual hoje? Procuraremos traçar algumas formas de práticas antigas que adquirem nova e maior pertinência na era atual (trabalho com os arquivos, a memó- 
ria, a relação entre o passado e o projeto, os objetos, a cultura material) e perspectivar novas oportunidades, novas práticas, novos objetos de estudo.

PALAVRAS-CHAVE: antropologia visual, era da reprodutibilidade técnica, era da transformação digital, hipermídia, narrativas visuais digitais.

\section{Introdução}

Pretendemos nesta breve reflexão inventariar algumas das transformações por que foi passando a antropologia visual desde que, em meados do século XIX, surgiram a fotografia, o cinematógrafo, o cinema, e que estes começaram a ser utilizados e questionados pela ciência em geral e, mais especificamente, pelas ciências sociais e pela antropologia. Acentuamos utilizados focando assim a perspectiva mais instrumental das tecnologias do som e da imagem como instrumentação de pesquisa e inquérito e como meio de divulgação, disseminação, comunicação e conhecimento. Não deixaremos, no entanto, de levar em conta o fundo e o contexto, isto é, as imagens e as sociedades e culturas que as utilizam e nas quais ganham relevo e uma concepção mais intemporal da dimensão antropológica das imagens (Belting, 2004).

\section{Antropologia visual da "era da reprodutibilidade técnica" e da expansão industrial à era da globalização e da transfor- mação digital}

$\mathrm{Na}$ investigação deste tópico, torna-se necessário situar o cinema e a antropologia num conjunto mais aberto das transformações sociais, econômicas, políticas e culturais. 
Revista de Antropologia, São Paulo, USP, 2005, v. 48 № 2.

Constatamos que o cinema e a antropologia de terreno têm, desde o seu nascimento, uma participação comum num mesmo processo de observação científica. O seu nascimento coincide com a sistematização da atitude analítica como um dos aspectos predominantes na atitude científica do século XIX e com a expansão industrial. O objeto da antropologia e do cinema situava-se sobretudo em sociedades, geográfica, física, material e culturalmente distantes das nossas (Piault, 1992). A sua evolução acompanha os processos sócio-históricos, como poderemos facilmente constatar nas primeiras décadas do século XX com o advento da montagem no cinema e o desenvolvimento da escola soviética, com o cinema direto nos anos de 1960 e com a fragmentação das narrativas e a crise das representações na década de 1980 .

O cinema (e a antropologia) tornou-se também parte da violenta estruturação da percepção espacial, social e cultural e da interação humana promovidas pelos modos de produção e pelo intercâmbio industrial capitalista (tecnologias modernas), e pela estruturação do espaço urbano (construção em larga escala de logradouros urbanos povoados por multidões anônimas). Podemos afirmar que a modernidade se concretizou no cinema e pelo cinema: primeiros filmes, instituiçóes cinematográficas, ascensão da linguagem visual como discurso social e cultural.

Se a viagem entre os continentes permitia alcançar a visão efêmera do outro, a fotografia e depois a câmara cinematográfica tornaram possível armazenar essas visões. Estas, construídas pelos operadores das novas máquinas, não eram inocentes. Transportavam consigo as interpretações subjetivas dos operadores, inseparáveis dos discursos dos respectivos impérios e dos objetivos institucionais da sociedade ocidental. As tendências visualizantes do discurso antropológico abririam também o caminho à representação cinematográfica das culturas. Constituindo como que um prolongamento do microscópio e de outra instrumentação científica da modernidade, os novos aparatos visuais mostravam o poder da 
José da Silva Ribeiro. Antropologia visual...

ciência em decifrar outras culturas, em tornar o outro objeto e espectáculo. Esta a grande ambivalência das origens do cinema: por um lado, instrumento de exibição do outro (arte de feira), por outro, a ligação com a ciência e a cultura.

As sociedades e as culturas permaneceram como que divididas em predominantemente observadas (fotografadas, estudadas, cinematografadas) e predominantemente observadoras (que fotografam, estudam, produzem filmes), orientais e ocidentais, sul e norte, pobres e ricas, rurais e urbanas, femininas e masculinas. Por outro lado, com a transformação do cinema em indústria, as preocupações científicas que marcam o início das primeiras imagens da reprodutibilidade técnica tornam-se suspeitas e merecedoras de reservas, porque excessivamente dependentes do poder econômico, das indústrias das imagens e das tecnologias, e da organização do trabalho (equipes de produção). A ciência e a antropologia permanecem sobretudo textuais, e à imagem pouco mais resta do que servir a propósitos de ilustração ou popularização da ciência. Essa tendência manter-se-á não obstante o desenvolvimento de muitas e boas práticas de utilização da imagem.

Os limites do trabalho na antropologia visual são sobretudo dependentes de três fatores: a dependência econômica, os constrangimentos técnicos que só nos anos 1960 permitiram o registo de som síncrono e de planos de longa duração, a dificuldade de trabalho com os filmes sem o recurso a pesados equipamentos (moviola) e a conseqüente separação da escrita como corrente dominante da produção científica em antropologia. O advento do vídeo nos finais dos anos 1960 não resolveu totalmente as limitações e os constrangimentos. A edição (montagem) continuou dependente de pesados investimentos, e as instituiçóes acadêmicas permaneceram mal equipadas. Só o advento da era digital do DV - “a utopia tornada máquina” (Sabouraud, 1999) - tornou definitivamente autônomo o investigador em sua tarefa de desenvolvimen- 
Revista de Antropologia, São Paulo, USP, 2005, v. 48 no 2.

to de seu projeto de passagem ao terreno e às imagens e, conseqüentemente, da realização de seus filmes e documentos visuais digitais. As razões evocadas de natureza epistemológica, decorrentes do estatuto e da natureza da imagem, encobrem, por vezes, complexas relaçôes de poder, o caráter conservador das instituições e a pouca abertura à sociedade e à inovação. Só as tecnologias digitais viriam a abrir brechas nesse edifício e a romper com alguns desses atavismos.

Com a passagem da era da reprodutibilidade técnica (Benjamin, 1936) para a era da transformação digital (Jenkins, 2003), emergem novas problemáticas. Os processos sociais e culturais da globalização aceleram-se (revolução digital) e tornam-se multipolares. Na realidade, trata-se de uma mudança vertiginosa jamais verificada anteriormente na história da humanidade, e os meios digitais são freqüentemente apresentados como o "motor" dessa mudança. Essa interpretação

oculta o processo de concentração econômica à escala global, que começou antes da revolução digital e implica grandes inovações em tecnologias tão díspares como a propulsão a jato e a tecnologia de satélite, os cabos de fibra óptica e o transistor; ignora os realinhamentos geopolíticos das últimas décadas desde as crises do petróleo e do colapso do comunismo, que levaram à transição de blocos de poder ideologicamente opostos para blocos de comércio neoliberais e capitalistas e aos mercados emergentes da Ásia e da América Latina; não considera a desregulamentação (i. e., as alterações jurídicas e institucionais) que tem vindo a afetar as indústrias de televisão nacionais e os monopólios de telecomunicações controlados pelo Estado ou por grandes grupos nos países industrializados. (Elsaeser, 2001, p. 101)

O digital, porém, tornou-se "metáfora cultural" de crise e transição - de passagem da "representação" para a "simultaneidade", "telepresença", "interatividade", "tele-ação". 
José da Silva Ribeiro. Antropologia visual...

Em relação ao cinema, o audiovisual não é muito mais que uma nova técnica de pós-produção, de apresentação, de armazenamento, de distribuição. Isso, no entanto, é uma parte da questão, pois o cinema digital em que a animação ou o componente gráfico é prioritário associa-se mais à pintura e à escrita como aplicação manual de talento e competência - regresso do "artista" e do autor como fonte e origem da imagem como meio mais expressivo que reprodutivo. Paralelamente a digitalização coloca em pauta crenças profundamente enraizadas na representação e na visualização e leva a reexaminar muitos dos discursos críticos, científicos e estéticos - baseados em nossa cultura.

A despeito dessas questôes, a produção torna-se cada vez menos dependente dos países do centro, do poder econômico ou das estruturas profissionais e dos interesses corporativos. Tornam-se caducas as categorias como "amadores" e "profissionais". Desenvolve-se uma intensa atividade de produção descentrada, nas margens, com base numa multiplicidade de pólos, que cada vez mais entram em processos de produção e de interação em rede.

Também se diluem as fronteiras entre os media. Os media digitais incorporam potencialmente todos os anteriores. Surgem novas concepções e representações das relações espaço-tempo (Augé, 1997; Castells, 2000) - relações entre distintos períodos, entre o presente e a memória, entre regiōes diferentes: a multilocalidade, as ligações interdisciplinares, as ligações intertextuais e discursivas (Clifford \& Marcus, 1986; Marcus \& Fisher, 1986; Marcus, 1991; 1994), a "hiperescrita” (textos híbridos, não lineares) entre diferentes meios e variados discursos (Stam, 2001). As tecnologias digitais tornam-se acessíveis a um número cada vez maior de utilizadores (democratização dos media), enquanto se melhora a sua qualidade técnica e se diluem também as fronteiras entre "amadores" e "profissionais" dos media. As tecnologias digitais tornam-se tecnologias da memória (arquivos digitais) suscetíveis de armazenar, organizar e co- 
municar uma grande quantidade de informação, de qualquer tipo e suporte (textos, imagens, sons, audioimagético), de fazer circular e tornar facilmente acessível e disponível simultaneamente numa pluralidade de lugares por um grande número de utilizadores - as bases de dados serão as formas simbólicas ou culturais contemporâneas, aparentemente caóticas mas estruturadas, nas quais se podem realizar um grande número de operações básicas: navegar, ver, organizar, reorganizar, selecionar, compor, enviar, imprimir etc. (Halbwachs, 1968; Levy 2001; Baer, 2003). Se, por um lado, está latente a ameaça de banalização ou da corrosão da forma inerente ao pensamento e à racionalidade (Postman, 1998), por outro, torna-se urgente encarar o desafio que as tecnologias digitais oferecem à investigação, ao ensino, à criação de espaços virtuais de produção, circulação e utilização do conhecimento e às profundas transformações que parecem produzir nas sociedades contemporâneas, de modo comparável à invenção do alfabeto (Castells, 2000). Surgem, também, novos desafios e novas áreas de investigação relacionados com a sociedade, a cultura e o conhecimento em rede - "sociedade em rede", "cibercultura”, "ciberantropologia", "cibersociedade", "etnologia das comunidades virtuais", "inteligência coletiva”, "antropologia digital”, que urge trazer para o centro da investigação na antropologia (Hine, 2000), com a convicção de que a sociedade, o pensamento e a cultura de cada época se refletem em sua técnica (Wiener, 1998)

$\mathrm{Na}$ convergência desses fatores, as tecnologias digitais e os computadores poderão ser, para o antropólogo e os cientistas sociais, muito mais úteis que meros processadores de textos, de imagens e sons e de codificação de dados recolhidos no terreno: um poderoso meio de (autoria) apresentação de resultados de investigação - como o filme em DVD, a hipermídia, o lugar de convergência com teorias e paradigmas de investigação (pós-estruturalismo, teoria crítica, teoria das redes) capazes de desenvolver uma apresentação mutissensorial (escrita, sons, imagens), 
José da Silva Ribeiro. Antropologia visual...

de relacionar dados com a interpretação, de justapor vozes e perspectivas, de permitir ao utilizador processos interativos de descoberta e de utilizaçao ativa e criativa no processo de aprendizagem, de gerar produtos culturais ou científicos para grandes públicos (Landow, 1995; Clement, 2000; Bairon, 2002).

As tecnologias digitais, além de potencializarem (facilitarem e generalizarem) as práticas tradicionais da pesquisa em antropologia em sua componente escrita, audiovisual e na organização e no desenvolvimento do processo de virtualização museológica (de arquivos e coleções), parecem também constituir um grande avanço na medida em que incorporam potencialmente todos os media anteriores, diluem as especificidades de cada um, facilitam a intertextualidade e a sua mestiçagem (Stam, 2002) e a integração dos três processos, das práticas ou tradições acima referidos.

As novas tecnologias digitais e sobretudo a hipermídia constituem uma forma, porventura mais eficaz, de integração da antropologia visual com a antropologia (escrita) e da antropologia com a antropologia visual; de imagens, sons e audiovisuais com a escrita; dos filmes com a reflexão teórica - todo o aparelho crítico do filme (produção, utilização, reflexão teórica); das práticas atuais com o regresso "à antropologia clássica, para melhor sondar os seus fundamentos práticos e intelectuais e abordar a questão da construção discursiva de seus objetos no texto etnográfico" (Kilani, 1994, p. 29). Essas novas práticas reconfiguram-se como um voltar a "caminhos muito antigos, ao prosseguir esta resposta à crítica da retórica etnográfica convencional” (Marcus, 1995, p. 52), às imagens iniciais, "verdadeiros arquivos vivos, conduzem a novas abordagens da antropologia e da história [...] a sua posição tem necessidade de ser precisada, as suas coordenadas devem ser elucidadas em relação às próprias condições da sua captação, do seu registo. A interrogação legítima sobre o estatuto destes dados passa definitivamente por um exame críti- 
co da sua realização" (Piault, 1992, p. 61), da tradição escrita e imagética com a tradição museológica - as coleções, os arquivos -, isto é, com a memória e conseqüentemente com o tempo presente e a história.

\section{Da documentação e preservação de práticas culturais ameaçadas às formas narrativas visuais e digitais}

A primeira função das imagens em antropologia foi (e é) documentar, isto é, criar algo portador de informação que traz em si a inscrição e o registo de um acontecimento observável ou verificável. As imagens poderiam funcionar nesse contexto dentro do espírito de recolha que informava a expansão industrial e colonial, do conhecimento antropológico e de sua dimensão museística.

As tendências visualizantes do discurso antropológico ocidental abriram o caminho para a representação cinematográfica de outros territórios e culturas. O estatuto "ontologicamente" cinético da imagem em movimento favoreceu o cinema não só em relação à palavra escrita mas também à fotografia. Montra da antropologia ao armá-la com a evidência visual não só da existência dos outros mas também da alteridade. O cinema, neste sentido, prolonga o projeto museístico de reunir na metrópole objetos zoológicos botânicos, etnográficos e arqueológicos tridimensionais. A diferença das mais reputadas e "inacessíveis" ciências e artes das elites, o cinema popularizador podia apresentar aos espectadores mundos não europeus, deixando-lhes ver e sentir civilizações estranhas. Podia transformar o obscuro mapa-múndi num outro mundo conhecido e familiar... Como produto da ciência e da cultura de massas, o cinema combinava as viagens com o conhecimento, as viagens com o espetáculo, e transmitia a idéia do "mundo como exposição" (Shohat \& Stam, 2002, p. 122 e 125). 
Margaret Mead precisava em 1979 os objetivos da antropologia de urgência e a função das imagens nesse processo: "A antropologia, ao agrupar diversas disciplinas [...] aceitou implícita e explicitamente a responsabilidade de reunir e de preservar documentos sobre costumes que desaparecem e sobre povos, quer estejam no estado natural, sem escrita, isolados em qualquer selva tropical, num canto perdido de um cantão suíço, ou nas montanhas de um reino asiático". Assim entendia ser da antropologia visual essa responsabilidade.

Sorenson refere a necessidade de preservar em documentos visuais quer os "modelos culturais de comportamento humano que ainda existem no mundo" e constituem "expressões diversas e por vezes únicas de capacidades humanas fundamentais", que nos informam sobre "uma larga gama das diferentes possibilidades que oferece o desenvolvimento humano, particularmente aquelas que desempenharam um papel na evolução dos nossos modelos de organização ligados às transformações ecológicas e econômicas", quer "as sociedades que se modernizam", permitindo-nos

aprofundar os nossos conhecimentos sobre a maneira como o homem se integra no mundo, opõe-se às suas transformações, ou integra as que ele mesmo engendrou. Estes novos modos de vida, tendo evoluído com a tecnologia, talvez mudem mais rapidamente ainda do que as culturas isoladas. O nosso conhecimento muito parcial da dinâmica de uma tal evolução ou do seu significado sociobiológico obriga-nos muitas vezes, pela escolha da sua orientação, a recorrer a decisões arbritárias, tomadas irrefletidamente. A marcha para o futuro será menos traumatizante e mais facilmente aceitável se os nossos conhecimentos forem maiores. (1979, p. 123)

Essa função inicial que caracteriza os filmes de investigação torna-se narrativa nos filmes de exposição. Nesses filmes trata-se de expor, ou reexpor, os resultados científicos já elaborados, isto é, de mediatizar no sen- 
tido de passar para outro medium, ou para o público por meio de um outro medium, um discurso científico. "Em muitos casos o filme pode expor certos aspectos da atividade humana com mais facilidade e eficácia do que o fariam um texto ou um discurso oral" (France, 1989, p. ii).

As instituições científicas reconhecem nos filmes de exposição características não só de qualidade instrumental, mas também de natureza simbólica (sistemas de símbolos e modo de estruturação, "gramática das imagens": modos de apresentação dos conteúdos, modos de construção da mensagem, caráter apelativo das imagens e das vozes do comentário), úteis à pesquisa e à comunicação científica e, no caso concreto, à etnografia e à antropologia.

A modalidade expositiva de representação, ao se dirigir diretamente ao espectador por meio de intertítulos ou vozes, expõe uma argumentação acerca de uma realidade, um acontecimento ou tema. Utiliza voz onisciente, exemplo típico ${ }^{1}$ é o do apresentador de notícias televisivas ou dos enviados especiais. Essa modalidade é mais próxima do ensaio, da informação expositiva clássica (simétrica), de uma conferência ilustrada com imagens, enquadrada no modelo clássico de comunicação-transmissão de informação (Meunier, 1994). Nesse proceso de comunicação, a centralidade é a escrita ou o comentário dirigido ao espectador, servindo as imagens como ilustração, demonstração ou contraponto. Prevalece sobretudo o som assíncrono. Pode, no entanto, recorrer-se ao som síncrono (som ambiente) para criar no espectador um efeito de realidade. A retórica da argumentação desenvolvida pelo comentário (pela voz do comentador) desempenha a função de dominante textual, fazendo que o texto esteja a serviço de uma necessidade de persuasão. A montagem serve sobretudo para estabelecer e manter a continuidade retórica mais que a continuidade espacial ou temporal e para provar a tese enunciada pela comentário. Podem, no entanto, introduzir-se justaposições e ligações inesperadas de imagens de modo a estabelecer pontos 
José da Silva Ribeiro. Antropologia visual...

de vista originais ou novas metáforas que o realizador talvez queira propor, introduzindo um nível de contraponto, contradição, ironia, sátira, surrealismo (formas de distanciamento?). Por vezes, contém entrevista ou depoimentos curtos. Estes, porém, estão subordinados a uma argumentação. A do próprio filme freqüentemente ocorre por meio de uma voz invisível onisciente ou de uma voz de autoridade proveniente da câmara que fala em nome do texto (interação mínima entre entrevistador e entrevistado). As vozes locais dos outros ficam entrelaçadas numa lógica textual que as inclui e orquestra; conservam escassa responsabilidade na elaboração da argumentação; são sobretudo usadas para apoiar, fundamentar provas ou justificar aquilo a que se faz referência no comentário. A voz da autoridade pertence ao próprio texto em vez daquela de quem foi recrutado (cooptado) para fazer parte dele.

O filme de exposição ou modo expositivo de representação pretende dar ou fazer passar a impressão de objetividade, racionalidade bem estabelecida, tendência para a generalização imposta pelo comentário (voz over), extrapolada com base nos exemplos concretos oferecidos pela imagem. Utilizando uma economia de linguagem que esquematiza a problemática, apresenta questões de modo sucinto e enfático por meio da eliminação da referência ao processo através do qual se produz, organiza e regula o conhecimento de modo que este também está sujeito aos processos históricos e ideológicos de que fala o filme.

Espera-se que o espectador dessa modalidade de exposição crie expectativas de que está perante um mundo portador de uma única racionalidade e de um conjunto de lógicas causa-efeito, antecedentes-conseqüentes, e diante da procura da solução de um problema ou enigma.

Outras formas narrativas de natureza exploratória constituem modalidade diferente de utilização da imagem na pesquisa etnográfica e na apresentação pública de formas acabadas. Essa se centraliza na prioridade dada à observação, à construção da narrativa baseada na imagem, às 
vozes e sonoridades locais, à utilização de arquivos documentais. É esse processo que melhor caracteriza o trabalho antropológico e que se tornou método tanto no cinema documentário (Flaherty, Vertov) como na antropologia visual (Rouch, MacDougall, John Marshall, Trinh T. Minh-há) (Ribeiro, 2004).

\section{Das coleções dos museus às múltiplas formas e suportes}

As primeiras imagens enriqueceram as coleções dos museus, os arquivos, as enciclopédias cinematográficas. Além da função de preservação das culturas atribuída à "antropologia de urgência" e de comunicação da ciência, desenvolvem-se práticas de constituição de acervos com múltiplas funções museológicas e de investigação como a realização de estudos sistemáticos e comparativos. São exemplos disso os museus de etnografia e também as cinematecas e fototecas.

$\mathrm{O}$ ato fundador dessa utilização das imagens em antropologia devese a L. F. Regnault ao se propor, a partir das imagens, a comparar atitudes, movimentos e técnicas, procurando assim criar as bases de uma ciência experimental cujas premissas seriam a psicologia étnica compara$d a$, baseada nas imagens, e a de identificação cultural do corpo e do movimento. Regnault com Azoulay iniciam a utilização dos rolos Edison para registrar o som, produzindo os primeiros fonogramas antropológicos. Em 1900, propõem no Congresso de Etnografia de Paris um verdadeiro programa de antropologia visual: elaboram um projeto de laboratório "audiovisual" de etnografia; defendem o emprego sistemático da imagem em movimento na pesquisa etnográfica; propõem a criação de arquivos antropológicos filmados. "Os museus de etnografia deveriam anexar às suas coleções cronofotografias." 
José da Silva Ribeiro. Antropologia visual...

$\mathrm{Na}$ Alemanha, o Institut fur den Winssenschaftlinchen Film (IWF), hoje IWF Wissen und Medie (conhecimento e media), institui um método que garante cientificidade e normatização documental - regras para a documentação filmada em etnologia e em ciências das tradições populares" - que formou os antropólogos alemães para filmarem na Melanésia, África, América e Europa ${ }^{2}$, recomendando atenção à exatidão científica, evitar referências ideológicas e a presença de estranhos à antropologia. Organizou cursos intensivos de cinema para antropólogos e preparou expedições. As regras instituídas exigiam que a filmagem fosse feita ou supervisionada por antropólogos experimentados, tendo o cuidado da exatidão e do rigor científico, que os fatos filmados fossem autênticos (consideravam, por exemplo, que os processos técnicos eram reconstituíveis, os rituais e as cerimônias não), que não se fizessem movimentos de câmara, nem se utilizassem efeitos ou tomadas de ângulos espetaculares, que a montagem tivesse como único objetivo ser representativa. Em 1952, Gotthard Wolf, diretor do Instituto, propõe o estabelecimento em Göttingen do primeiro arquivo sistemático do filme etnográfico, e Konrad Lorenz trabalha desde o início na compilação e organização da Enciclopédia Cinematográfica.

$\mathrm{O}$ interesse pelo recolhimento e coleção de imagens do mundo foi não apenas dos etnólogos. $\mathrm{O}$ banqueiro Albert Khan se propôs a realizar o primeiro arquivo cinematográfico na França, Les Archives de La Planète. Graças a ele foi criado o Comitê Nacional de Estudos Sociais e Políticos e foi financiada a primeira cadeira de Geografia Humana no Collège de France, com Jean Brunhes como titular; foi organizada a primeira memória do que mais tarde, após a Segunda Guerra Mundial, denominou-se etnografia ou antropologia de urgência - perante a necessidade de registrar, antes que fosse tarde, as atividades e os comportamentos humanos em vias de desaparecimento com o advento e a difu- 
são da modernidade. Albert Khan empreendeu, orientado por Jean Brunhes, um programa sistemático de registro cinematográfico do mundo inteiro (ambiente construído e natural, formas de expressão religiosa e cívica), que deveria estar disponível para especialistas e políticos.

Esses atos fundadores viriam a ser exemplo e modelo para algumas instituições museológicas e acadêmicas. Hoje, com o desenvolvimento das tecnologias digitais, o processo pode generalizar-se, cabendo aos antropólogos visuais a missão de orientar a conservação, animação e divulgação de coleções e arquivos de empresas, instituições públicas, famílias. Encontram-se em risco de irremediável perda documentos visuais (fotografias, filmes e vídeos) nos mais diversos contextos, fazendo parte dos processos sociais neles existentes (contextualizados) fotografias e filmes de família ${ }^{3}$, empresa, escola, associações culturais, coleções de fotógrafos e cineastas amadores e profissionais.

Poderíamos apontar alguns projetos exemplares ${ }^{4}$ dessa prática realizados por uma grande diversidade de instituições. Não o permitindo a natureza deste texto, indicamos o projeto ${ }^{5} \mathrm{HADDON}$, dirigido por Marcus Banks do Institute of Social and Cultural Anthropology da Universidade de Oxford. Este se propõe tanto a recuperar os filmes de interesse etnográfico para instituiçôes diversas e para colecionadores particulares na Inglaterra e em diversos países europeus, nos Estados Unidos, no Canadá e na Austrália como a reunir num catálogo único, uma base de dados eletrônica, toda a informação acerca desses filmes. Uma das originalidades do projeto de investigação é o de solicitar a colaboração aberta, de um site na Web, a toda a população que puder contribuir para a sua realização e aos interessados em sua utilização. 


\section{Da objetividade, como auxiliar de pesquisa aos novos paradigmas epistemológicos}

A primeira e a mais simples utilização das imagens na investigação em ciências sociais e, mais especificamente, na etnografia e na antropologia, foi (e é) como auxiliar de pesquisa. Nessa situação as tecnologias da imagem constituem instrumentação de pesquisa ou "instrumento do conhecimento". São reconhecidas ou atribuídas a elas características específicas, úteis à pesquisa científica no quadro de alguns paradigmas de investigação (Ribeiro, 2003, cap. VI e II) (positivismo, naturalismo): a sua relação com o referente - a realidade de que constitui índice (Pierce) -, a transparência tecnológica (muitas vezes manifesta nos discursos do quotidiano); a observação encoberta (câmara oculta), a observação totalmente participante.

Nesse processo de utilização, as imagens permanecem rigorosamente controladas pelos métodos tradicionais de inquérito. A sua utilização não os modifica. É comumente aceito pela comunidade científica (micromeio dos especialistas) que a partir de finais do século XIX inicia sua utilização ${ }^{6}$. A instrumentação científica introduzida no processo de pesquisa é apenas complementar dos métodos tradicionais: funciona como instrumento de prova e controle, de análise minuciosa e detalhada e como bloco de notas extraordinariamente eficaz. É geralmente admitida a eficácia da utilização dos registros cinematográficos e videográficos no estudo dos comportamentos corporais, rituais, materiais que se desenvolvem num determinado espaço e tempo - "atividades exteriores humanas”. Às atividades interiores (representaçôes mentais ${ }^{7}$ ) o acesso sobretudo faz-se por meio da palavra-fala ou com o apoio da palavrafala (vozes locais). Daí a importância dos registros de áudio.

Essa é uma prática antiga que remete às primeiras expedições científicas e à realização pioneira do trabalho de campo. A câmara fotográfica 
Revista de Antropologia, São Paulo, USP, 2005, v. 48 № 2.

(e por vezes a cinematográfica) acompanhou quase sempre o antropólogo em suas deslocalizações. Malinowski refere em seu Diário em sentido estrito uma grande quantidade de vocabulário relacionado com a sua utilização e com o ato fotográfico: revelar (1985, p. 85), transportar películas, placas e o equipamento necessário (p. 218), reparar o aparelho (p. 243), anotar os elementos a fotografar (p. 218), discutir a fotografia com seu assistente (p. 243). Malinowski explica ainda que fez uma série de fotografias (p. 88), alguns clichês (p. 261), danças cerimoniais (p. 88), canoas (p. 241), trocas de alimentos (p. 264), caramanchóes (p. 285), visando indivíduos, objetos ou ações puramente típicos da cultura local, e confessa a sua negligência ao esquecer a película apesar do projeto de fotografias a fazer (p. 177), lamentando não o ter feito em determinados elementos (p. 239).

Historicamente as origens da antropologia visual assentam em pressupostos positivistas ${ }^{8}$, isto é, que uma realidade objetiva é observável e que o rigor da observação é dependente dos métodos de pesquisa. No entanto, freqüentemente se admite a natureza socialmente construída da realidade cultural e a natureza experimental de nossa compreensão de qualquer cultura, e é nesse contexto que de modo habitual se situa a antropologia visual, identificada por vezes como pós-estruturalista e pós-modernista.

Alguns autores consideram que a antropologia visual (o filme) antecedeu ao texto nas interrogações sobre a representação antropológica e questiona-a de uma maneira mais profunda do que se poderia prever: "bem à frente da representação da escrita, os filmes documentais e etnográficos começaram a tomar consciência das dificuldades implicadas na representação de outros mundos e pessoas através do medium imagens e da forma particular das histórias da cultura euro-americana" (Devereaux, 1995, p. 332).

Noções como a de "terreno", lugar objetivo circunscrito no espaço e tempo, "presente etnográfico" e as formas objetivistas e realistas de re- 
presentação da realidade são postas em causa em favor de uma antropologia multissituada (no espaço, tempo e posicionalidade), visando harmonizar a mobilidade das forças sociais (deslocalização) com a sua fixidez (local). A voz invisível onisciente dá lugar a uma pluralidade de interpretaçóes (situadas) dos fenômenos sociais (pluralidade de vozes) e às formas dialógicas de abordagem do "terreno" e de construção discursiva, remetendo a formas mais criativas, mais conscientes e mais participativas de escrita sem perda das qualidades da investigação acadêmica do passado (Anderson, 1999). O investigador torna-se presente desvelando ou mostrando a experiência do antropólogo no terreno, o seu lugar de observação, as relações estabelecidas, os saberes aí adquiridos ou construídos a partir daí. Inscreve a sua experiência pessoal num duplo contexto, o da relação com os observados (diálogo de mediação entre si e o outro) e o da relação com os leitores ou espectadores (comunicar a sua compreensão da experiência ao outro, simular para o leitor um mundo possível de significações e de açôes, um mundo que lhe "fala").

A modernidade da escrita do texto etnográfico reside, precisamente, neste traço que o antropólogo deixa da sua experiência e na pertinência desta experiência na construção do objeto. $\mathrm{O}$ conhecimento antropológico regese cada vez mais por um contexto no qual o informador e o antropólogo procuram estabelecer uma base comum de compreensão. $\mathrm{O}$ que se cria nesse encontro é uma espécie de lugar intermediário entre duas culturas. É "um momento de pensamento intercultural". (Clifford, 1980, p. 529)

É nesse sentido que é preciso repensar o processo social e intelectual, a partir do qual surgem as descriçôes e se constrói o texto etnográfico. Atribuindo assim à palavra "dada" o seu sentido etimológico de "coisa dada" (id.), de coisa trocada entre dois sujeitos; e à cultura - tanto a do antropólogo como a do informador -, a sua dimensão dinâmica de cons- 
Revista de Antropologia, São Paulo, USP, 2005, v. 48 no 2.

trução, de negociação e de contestação dos pontos de vista" (Kilani, 1994, p. 34).

Clifford sugere também que, embora a etnografia não possa escapar ao reducionismo, pode se mover além das molduras historicamente abstratas (1988, p. 23). Seguindo essa via, a hipermídia etnográfica pode ser um meio de expandir determinados aspectos tradicionais da etnografia, tais como a estrutura narrativa, a intersubjetividade, a plurivocalidade, as linearidades e a utilização pedagógica. Contendo potencialidade de conjugar várias formas de análise, de reflexão, de interpretação e de vozes (incluindo a dos sujeitos da pesquisa), a hipermídia tem o potencial de ir além do processo de "descrever" a cultura para tentar o centro da própria "experiência da cultura". Experiência como processo em que o utilizador da hipermídia poderá adotar ao fazer seu estudo e a análise antropológica, projetar a própria pesquisa, interpretar de formas múltiplas a informação etnográfica (Anderson, 1999).

Assim acontece com o trabalho do investigador em antropologia, já em si hipermidiático na medida em que constitui um processo de observação multissensorial; de elaboração das inscriçóes locais - registros, transcrições -; de ligações entre saberes (locais e globais, microssociais e macrossociais, concretos e abstratos, produtos de múltiplas abordagens científicas, jornalísticas, artísticas etc.), entre dados e teoria; de aprendizagem por tentativas repetidas baseadas na imersão no terreno. A própria situação do trabalho de campo poderá ser entendida como um processo de imersão semelhante ao do utilizador no hipertexto/hipermídia, embora de natureza muito mais complexa (liminaridade, trajetórias não lineares, metamorfose, multiplicidade, descentramento, orquestação), e a apresentação final dos resultados (integração da experiência realizada na instituição antropológica) é uma forma de criar todo o tipo de ligações múltiplas entre dados e interpretação, múltiplos intertextos, decorrentes de múltiplas vivências, qualidades perceptivas, perspectivas de 
José da Silva Ribeiro. Antropologia visual...

observação e análise, de confronto entre os dados e a teoria, ou mesmo a seleção e utilização dos media que se vão incorporando à investigação e à relação com o terreno, os pares, a comunidade científica, as instituições. Retornando a Vertov, a realização de um filme, ou o desenvolvimento de um projeto de pesquisa e a conseqüente escrita de um texto, ou outra forma de apresentação da pesquisa é um processo de montagem (Piault, 2000; Tomas, 1994; Ribeiro, 2000; Bairon, 2003), e esta é regida por uma regra - a das aproximaçóes sucessivas (Rouch, 2004).

Permitindo armazenar, organizar uma grande quantidade de informação proveniente de uma multiplicidade de meios e torná-la facilmente acessível e utilizável, as tecnologias digitais e a hipermídia tornam possível apresentar todo o percurso de um investigador, articular o processo desenvolvido ao longo de décadas e conduzem a contínuas reescritas do percurso: a historicidade de uma comunidade, de um povo, de uma instituição e a possibilidade de uma infinidade de processos criativos de interligações e de reflexão acerca desses processos de interligação e de “intertextualidades eletrônicas” (Darley, 2003).

\section{Do registro das técnicas materiais e rituais e das palavras e sonoridades para os novos campos da antropologia - antropologia da arte, antropologia do design, cultura visual}

A antropologia visual ou antropologia da comunicação visual ${ }^{9}$, como alguns autores preferem denominar essa área de investigação-ensino (Sol Worth, Jay Ruby, Massimo Canevacci, Paolo Chiozzi), centra-se em três objetivos principais: a utilização das tecnologias de som e da imagem na realização do trabalho de campo (qualquer que seja a situação em que esta faça parte da estratégia mais adequada de pesquisa); a construção de discurso ou narrativas visuais (o uso das tecnologias na apresentação dos 
resultados da pesquisa - nos museus, no ensino, na comunicação com o grande público - na estruturação da narrativa fílmica, ou de multimídia e hipermídia, e em sua realização) e o desenvolvimento de retóricas convincentes (de boas práticas), quer no meio acadêmico, quer para os públicos e para as funçôes a que se destinam os produtos resultantes; a análise dos produtos visuais - em primeiro lugar, os produtos resultantes do trabalho dos antropólogos com vista ao estabelecimento de critérios de apreciação, avaliação e aquisição de boas práticas e de formas de aprendizagem da antropologia e do cinema, mas também outros produtos visuais e audiovisuais, elementos da cultura visual ${ }^{10}$ (discursos visuais e audiovisuais), "o cinema (ficção ou documentário), a televisão, a fotografia, a videomusic, a publicidade, a videoarte, o ciberespaço" (Canevacci, 2001, p. 7-8), que permitam o conhecimento da sociedade e da cultura e o desenvolvimento da teoria em ciências sociais.

A produção e análise das representações fotográficas e concebidas para a tela (écran), ou mais simplesmente a intersecção entre a cultura e os media (Ginsburg, 1999, p. 36).

O campo da antropologia visual inclui três domínios separados, embora interdependentes: 1 . O estudo das manifestaçôes visuais da cultura - expressão facial, movimento corporal, dança, vestuário e adornos corporais, uso simbólico do espaço, ambiente arquitetural e construído, os objetos. 2. O estudo dos aspectos picturais da cultura, das pinturas das cavernas a fotografias, filmes, televisão, vídeo doméstico, etc. 3. O uso dos meios visuais para comunicar o saber antropológico. (Pink, 1992, p. 124)

Os primeiros filmes etnográficos tiveram como objeto de estudo as técnicas materiais e rituais, a vida quotidiana de povos exóticos sem fala, e eram mudos. Mas essa vida quotidiana vai ganhando voz e sonorida- 
José da Silva Ribeiro. Antropologia visual...

des (Chronique d'un été, Rouch, 1961). E a voz e as sonoridades tornaram-se importantes objetos de pesquisa. Alguns antropólogos, como Sara Pink, referem manifestações visuais da cultura, aspectos picturais da cultura. Há autores que apontam novos objetos para a disciplina, como a antropologia do objeto, ou a antropologia do design, e a antropologia da arte fortemente relacionadas com a antropologia visual.

Mirzoeff, ao propor a cultura visual como um campo de estudo e ao identificar a necessidade de interpretar a globalização pós-moderna do visual como parte da vida quotidiana (essa questão também foi levantada por Geertz), abre novos campos de observação e análise e novos âmbitos para a antropologia visual.

\section{Como repensar atualmente a antropologia visual no âmbito da antropologia?}

Nem sempre a relação entre a antropologia e a antropologia visual foi pacífica. Os antropólogos desconfiaram das imagens ao mesmo tempo em que mantiveram uma secreta esperança de que estas lhes resolvessem alguns problemas (o da objetividade). Mantiveram essa insuportável ambigüidade. Porém, desde o início, foram os antropólogos que teimaram em procurar o outro cineasta para compreender o que faziam. Assim integraram fotógrafos e cineastas nas missões científicas e procuraram estabelecer pontes entre os antropólogos e documentaristas (cartas de Rivers a Vertov). Por outro lado, cineastas desenvolviam conceitos importantes para a antropologia espontânea. Robert Flaherty realizava uma metodologia de terreno semelhante à dos antropólogos - longa permanência no terreno, subordinação da experiência local a uma idéia (ponto de vista documental mais tarde desenvolvido por Jean Vigo), participação colaborativa de modo a melhor compreender "o ponto de vis- 
Revista de Antropologia, São Paulo, USP, 2005, v. 48 no 2.

ta do nativo". Vertov desenvolveu uma teoria da montagem em tudo semelhante ao processo de investigação em ciências sociais - a observação como montagem (construção), a organização dos fragmentos de película em função de índices (hipóteses interpretativas), a montagem final subordinada a uma idéia geral do filme - a da escrita em antropologia. Também os cineastas e os teóricos do cinema procuraram aperceber-se do que se passava do outro lado (Buñuel, Vigo, Grierson ${ }^{11}$, Wiseman, Depardon ou teóricos do cinema como Bergala, Aumont).

Nos anos 1980, Claudine de France traçava assim o cenário das relaçôes entre a antropologia e o cinema:

Verificaram-se algumas mudanças no filme etnográfico. Os antropólogos utilizam cada vez mais a imagem animada; os que filmavam preferencialmente os povos colonizados, agora tornados independentes, deslocaram os centros de interesse do filme etnográfico; as técnicas de registro e de leitura videográficas ligeiras, miniaturizadas estão à disposição de todos, encorajando os menos ousados, dissipando as últimas resistências ao olhar deste novo meio de investigação e apresentação. A produção de filmes ou de simples documentos filmados está consideravelmente desenvolvida e diversificada. $\mathrm{O}$ aumento das produçōes, constituindo quer inquéritos acabados autônomos, quer integrações "multimídia", ou formas de complemento audiovisual ao inquérito clássico, contribuiu indubitavelmente para o desenvolvimento desta nova disciplina: antropologia visual (Mead), etnocinematografia (Adriaan Gerbrands), para Claudine de France, antropologia fílmica (e praxeologia fílmica), porque o uso da cinematografia dá origem a métodos e procedimentos de (mise-en-scène) encenação próprios e levanta problemas epistemológicos específicos. O filme, onipresente na cena científica, tornou-se o equivalente ao caderno de notas, instrumento do inquérito clássico à obra escrita, à vitrina de exposição. (France, 1989) 
Atualmente procura-se, por um lado, situar o filme etnográfico no conjunto de outras práticas dos media, na representação da cultura não apenas como processo de produção mas também de recepção (media como terreno da antropologia) (Banks, 1990; Martinez, 1992; Canevacci). Para Ginsburg, a vitalidade da antropologia visual não dependerá tanto de sua institucionalização ${ }^{12}$, mas das múltiplas "relações estabelecidas entre o mundo disciplinar da antropologia e o universo mais arrojado da prática de filmes e vídeos" (1999, p. 33) que a possam levar a uma maior integração na antropologia, abrindo-a a novas temáticas, novos terrenos, novas produçóes.

Nesse sentido, a antropologia visual "abre novos campos de exploração e novos terrenos" e "uma nova maneira de conceber a antropologia" (Piault, 1999, p. 16). Estes, surgidos pelo "efeito singular de sociedade", pela pressão dos estudantes em fazer entrar o cinema na prática de estudo e no trabalho de campo perante a precariedade de inovação nas instituições acadêmicas.

\section{O que fazer com a antropologia visual hoje?}

A antropologia visual hoje adquire um novo fôlego e uma maior audácia. É um lugar de oportunidades. Medievalistas franceses ${ }^{13}$ e alemães adotam-na e formulam, dentro da antropologia histórica, uma antropologia das imagens (Jean-Claude Schmitt, Hans Belting). Os historiadores recorrem cada vez mais ao cinema como fonte para outros estudos da história (Marc Ferro, Robert Rosenstone, Peter Burke). Os cineastas e os teóricos do cinema entendem não ser possível o estudo do cinema sem o recurso às ciências sociais e à antropologia (Bergala, Aumont). A antropologia institui o cinema como terreno ${ }^{14}$ (Weakland, 1995; Canevacci, 1990; Stam \& Shohat, 1995). 
Revista de Antropologia, São Paulo, USP, 2005, v. 48 No 2.

As tecnologias digitais trazem contribuições inovadoras para as novas práticas de trabalho em antropologia não só como instrumentação de trabalho de campo, mas também de organização e tratamento da informação, realização, montagem, produção e circulação-divulgação, e também como meio e modo de análise. Com efeito, conceitos como o filme como texto ${ }^{15}$ foram objeto de análise minuciosa, dando-se particular atenção às estruturas formais, introduzidas nos anos 1920 na teoria do cinema e recorrentemente retomadas nos anos 1960 nos Cahiers $d u$ Cinéma por Noël Burch, que associa a reflexão teórica a uma observação fina (agudeza de observação) e concreta de seus elementos constituintes e de sua articulação, tornando-se finalmente exeqüíveis com o recurso a softwares de análise de som e imagem (TRANSANA, MARVEL, VIRAGE, ATLAS.ti, HyperRESEARCH).

A política e a técnica de edição em suporte digital (DVD, SVCD e formatos de acesso on-line) tornaram acessível uma ampla base documental, permitindo o desenvolvimento sistemático de estudos e a troca de informação ${ }^{16}$ entre núcleos de investigadores ao mesmo tempo em que estimulam e modelam o tratamento de arquivos (institucionais ou familiares) ou a criação de documentos visuais e sonoros da memória (história oral).

A cultura visual como marca indelével de nossa contemporaneidade fornece um amplo campo de estudo, por exemplo, a antropologia do design.

A antropologia visual apresenta-se como um campo de investigação e de desenvolvimento de práticas que constituem um desafio aos estudantes e às instituições universitárias no âmbito das atuais mudanças do ensino superior. Constitui-se como amplo campo interdisciplinar entre as ciências sociais e as artes, as ciências e as tecnologias da comunicação. Institui-se como processo simultâneo ou complementar de investigação e produção escrita, audiovisual, multimídia, hipermídia. Desloca-se das 
José da Silva Ribeiro. Antropologia visual...

temáticas tradicionais de investigação em antropologia para as temáticas atuais, sem no entanto deixar de tratar de toda a tradição antropológica e, simultaneamente, recuperar arquivos documentais das práticas anteriores, criando assim uma relação mais próxima e mais implicada (da disciplina e da universidade) na vida social. Abre oportunidade de empregabilidade não apenas num sentido mais restrito de acesso ao mercado de trabalho, mas de criação de novos empregos (novas práticas), novos "atores da cultura", figuras híbridas, misturando profissionais e amadores, amadores que se tornam os primeiros "profissionais" da expressão do futuro, como é o caso dos internautas, tornando caducas as categorias de "amadores" e "profissionais" (Alard, 1999, p. 25). Simultaneamente virada para o trabalho de campo, para a comunicabilidade, para o trabalho em rede e para as dinâmicas de interação em grupo (ou em comunidades de prática), a formação em antropologia visual remete continuamente à mobilidade dos estudantes e dos docentes não só como estratégias de abertura no âmbito da formação, mas também da produção e como ritual de passagem para a investigação-produção científica que emerge da sociedade e voltada para a sociedade.

Os atuais programas de formação em antropologia, que aos poucos começam a se difundir por toda a Europa e a se adicionar aos tradicionais centros de formação em antropologia visual (EHESS, Universidade de Nanterre, Universidade de Manchester), parecem sensíveis a essas questões. Assim, com as mais diversas denominações, enquadramentos, fundamentaçôes epistemológicas e importância no currículo, institucionalizam-se a antropologia visual e as suas práticas na formação de base em antropologia (1 Ciclo do Ensino Superior). Na LSE School of Economics and Political Science, em antropologia digital centrada em práticas inovadoras de ensino, sobretudo nas disciplinas Ler outras culturas - a interpretação antropológica do texto e do filme e Cog- 
nição e Antropologia; na Universidade de Manchester, Antropologia visual e Cultura visual; na Universidade de Lyon, Antropologia da comunicação; a Universidade de Paris VIII oferece uma formação mais variada e completa com História e atualidade da antropologia visual e o Etnólogo e a câmara, no âmbito dos métodos e das técnicas de investigação em antropologia, Técnicas da imagem e do som, Composição pesquisa multimídia, A representação no cinema do real no âmbito da Unidade de Ensino Media e Audiovisual. Na Universidade de Oslo, existe a área de especialização Cultura e comunicação (antropologia, sociologia e meios de comunicação). Na Bélgica, a Universidade de Lovaina, no âmbito do diploma de Estudos Aprofundados em Antropologia (3ํㅡㄴ Ciclo), além de Ateliê de antropologia audiovisual como um dos campos da antropologia, oferece formação em Dispositivos multimidia interativos - abordagem semiótica e antropo-sociológica, Seminário de investigação sobre a narrativa mediática, Antropo-sociologia da informação e da recepção mediáti$c a$, inserindo-a numa unidade específica de Tecnologias das Técnicas e dos Saberes.

$\mathrm{Na}$ Universidade Aberta, o programa de investigação-formação em Antropologia visual (cultura, conhecimento e media) centra-se em cinco programas que se enquadram no mestrado em Relaçóes Interculturais e no doutoramento em antropologia, com especialidade em antropologia visual:

Antropologia das imagens - estudos das imagens, isto é, estudos das técnicas e dos dispositivos visuais e de seu processo diacrônico - histórias das imagens e da antropologia (imagens como forma histórica), mas também como forma intemporal que o homem jamais deixa de inventar - o imaginário, as imagens mentais. Nesse contexto de imagens materiais e mentais, externas e internas, o cinema constitui a melhor demonstração do caráter antropológico da imagem. 
Trabalho de campo e Narrativas visuais digitais - Passagem ao terreno passagem à imagem ou metodologia de pesquisa e de produção audiovisual e multimídia-hipermídia em antropologia.

Vozes e sonoridades locais - estudo das vozes e sonoridades sociais e da construção de sua representação nos produtos audiovisuais e multimídia.

Cultura, sociedade e novas tecnologias - impacto das tecnologias digitais na cultura e na sociedade, na pesquisa em ciências sociais e na relação entre conhecimento e novos media.

Cultura visual - estudo (exploração) das expressōes visuais por meio de uma abertura da obra de arte e de outras formas de discursos visuais (design, media, manifestações visuais populares), constituindo uma abordagem multi e interdisciplinar (antropologia visual, sociologia da cultura, semiótica, filosofia da linguagem, tecnologia) e de integração metodológica de antigos e novos métodos de abordagem da cultura e da cultura visual.

\section{Notas}

1 Exercício: gravar um telejornal e estudar o que dizem as imagens, o que diz o comentário do jornalista e verificar a brecha que existe entre ambos.

2 Em Portugal, no Museu de Etnologia, existem 14 filmes produzidos com a colaboração do IWF e a orientação científica dos investigadores portugueses Ernesto Veiga de Oliveira e Benjamim Enes Pereira. Esses filmes revelam a prática metodológica do Instituto e as suas limitaçóes. A atividade técnica parece ser o objeto do filme, e a ritualidade do processo está atenuada ou ausente.

3 Ver a esse respeito a obra já extensa de Miriam Ferreira Leite sobre fotografias de família e a investigação coordenada por Roger Odin sobre os filmes de família (1995).

4 Recursos digitais para o ensino em antropologia: http://www.columbia.edu/dlc/ dart/; National Anthropological Archives and Human Studies Film Archives: http: //www.nmnh.si.edu/naa/. 
5 http://www.bodley.ox.ac.uk/external/isca/haddon/HADD_home.html

6 Ver Ribeiro (1993), As imagens da ciência - http://bocc.ubi.pt/pag/ribeiro-jose-asimagens-da-ciencia.html.

7 "Uma representação pode existir no próprio interior do utilizador; trata-se então de uma representação mental. Uma recordação, uma hipótese, uma intenção são exemplos de representações mentais. O utilizador e o produtor da representação mental são o mesmo. Uma representação pode também existir no ambiente do utilizador como este texto, por exemplo. Trata-se então de uma representação pública. Uma representação pública é geralmente um meio de comunicação entre um produtor e um utilizador distintos um do outro... Cada membro do grupo tem no seu cérebro milhōes de representações mentais, umas efêmeras, outras conservadas na memória a longo prazo e que constituem o "saber" do indivíduo" (Sperber, 1989, p. 76).

8 Ver http://www.unige.ch/ses/socio/cours/maggi/Diaporama_presentation.pps.

9 Essa denominação ou esse conceito, elaborado inicialmente por Sol Worth nos princípios da década de 1970, constitui uma abordagem que, segundo Jay Ruby, articula o estudo antropológico de todas as manifestaçóes visuais e pictóricas da cultura - movimento corporal, dança, atuação-representação-encenação, ornamentos, uso do espaço -, com a construção do meio em todas as representações da imagem - pintura, fotografia, cinema, televisão, novos media -, juntando-se a esse objetivo o da preocupação pela produção de imagens com uma intenção antropológica.

10 Recorde-se o que Jay Ruby, acima citado, refere como manifestaçôes visuais e pictóricas da cultura que constituem objeto de estudo da antropologia visual (ou da comunicação visual).

11 O sociólogo e cineasta John Grierson, em 1926, viria mesmo a usar pela primeira vez o conceito de cinema etnográfico como produção criativa baseada na realidade, distinguindo-a de outras formas como filmes de viagem, atualidades, noticiários, reportagens.

12 Só em 2001 a American Anthropological Association (AAA), por meio da seção para a antropologia visual, Society for Visual Anthropology (SVA), criou um guia de avaliação de filmes - http:/www.societyforvisualanthropology.org/Resources/ svaresolution.pdf.

13 Ver documentação (escrita, visual e sonora) do seminário Histoire des images et des représentations dans l'occident médiéval - http://semioweb.msh-paris.fr/AAR/387/ home.asp?id=387. 
14 Os estudos antropológicos dos filmes de ficção (feature films) teve início nos Estados Unidos durante a Segunda Guerra Mundial.

15 Falar do filme como texto é considerá-lo como discurso significante, analisar os seus sistemas internos e estudar as configuraçôes significantes que nele se podem observar (Aumont et al., 1989, p. 203).

16 Ver as temáticas do encontro ítalo-francês Etica di Internet que foi realizado em Roma, sobretudo a comunicação de Franco Carlini, Le teorie del dono e le dinamiche dell'altruismo in rete, em http://www.france-italia.it/index.php?lingua= it\&menu=1\&cont=1804\&citta=. Salienta Carlini que a tecnologia criou formas de cooperação anteriormente impensáveis, semelhantes às de uma economia prémercantil. Uma cultura difusa, à escala global, baseada na dádiva de bens imateriais (culturais e de conhecimento), que se repercute no modelo de negócio e no comportamento da empresa e da organização.

\section{Bibliografia}

ANDERSON, K. T.

"Ethnographic hypermedia: transcending thick description", in Department of Anthropology University of Massachusetts-Amherst. Disponível em <http:// cc.joensuu.fi/sights/kevin.htm>.

APPADURAI, A.

2004

Dimensôes culturais da globalização, Lisboa, Teorema.

AUGÉ, M.

1997

"Le nouvel espace-temps de l'antropologie", in Dires les autres, Lausane, Editions Payot.

AUMONT, J.; BERGALA, A.; MARIE, M.; VERNET, M.

Estética del cine, espacio filmico, montaje, narración, lenguaje, Barcelona, Paidós Comunicación. 
Revista de Antropologia, São Paulo, USP, 2005, v. 48 № 2.

BAER, A.

2003

"Tecnologías de la memoria: la tranformacion/redefinicion del recuerdo colectivo en la sociedad de la información", Cuadernos de Realidades Sociales, 53, p. 163-184.

BAIRON, S.

2002

Interdiscilinaridade: educação, história da arte e hipermídia, São Paulo, Futura.

BANKS, M.

2001

Visual methods in social research, London, Sage.

BELTING, $\mathrm{H}$.

2004

Pour une anthropologie des images, Paris, Gallimard.

BENJAMIN, W.

1992 [1936] Sobre a arte, técnica, linguagem e politica, Lisboa, Relógio d'Água.

BURKE, $\mathrm{P}$.

2004

Testemunha ocular, história e imagem, São Paulo, EDUSC.

CANCLINI, N. G.

2004 Diferentes, desiguales y desconectados, Barcelona, Gedisa.

CANEVACCI, M.

2001 Antropologia da comunicação visual, Rio de Janeiro, DP\&A.

CASTELS, M.

$2000 \quad$ A sociedade em rede, São Paulo, Paz \& Terra.

CHARNEY, L. \& SCHWARTZ, V. R.

2004 O cinema e a invenção da vida moderna, São Paulo, Cosac \& Naify.

CLEMENT, J.

2000

Du texte à l'hypertexte: vers une épistémologie de la discursivité hypertextuelle, http://www.educnet.education.fr/dossier/livrelec/lecture.htm 
CLIFFORD, J. \& MARCUS, G.

1986 Writing the culture, the poetics and politics of ethnography, Berkeley, University of California Press.

\section{DEVEREAUX, L.}

1995

"Experience, representation, and film", in DEVEREAUX, L. \& HILLMAN, R. (eds.). Fields of vision, essays in film studies, visual anthropology, and photography, Berkeley and Los Angeles, University of California Press, p. 56-73.

DUBOIS, P.

2004 Cinema, video, Godard, São Paulo, Cosac \& Naify.

ELSAESER, T.

2001

"Cinema digital, apresentação, acontecimento tempo", in Cinema Digital, Porto, 2001.

EPSTEIN, J

s/d

Lintelligence d'une machine, Paris, Jacques Melot.

FOUCAULT, M.

1995 A arqueologia do saber, Rio de Janeiro, Forense Universitária.

FRANCE, C. de

Cinéma et anthropologie, Paris, Éditions De La Maison des Sciences De L'Homme.

HALBWACHS, $M$.

1968 La mémoire collective, Paris, PUF.

HINE, C.

2000 Virtual ethnography, Londres, Sage Publications.

HOCKINGS, P. (Ed.)

1995

Principles of visual anthropology, New York, Mouton de Gruyter.

JENKINS, $\mathrm{H}$.

2003

"The work of theory in the age of digital transformation". Disponível em: $<$ http://web.mit.edu/21fms/www/faculty/henry3/pub/digitaltheory.htm>. 
Revista de Antropologia, São Paulo, USP, 2005, v. 48 No 2.

JEUDY, H.-P.

1995

Sociedade transbordante, Lisboa, SéculoXXI.

KILANI, M

1994

Linvention de l'autre, essais sur le discours anthropologique, Lausanne, Payot.

LANDOW, G. P.

1995 [1992] Hipertexto, la convergencia de la teoría crítica contemporânea y a tecnología, Barcelona, Paidós.

LEVY, P.

2001

O que é o virtual? Lisboa, Quarteto Editora.

MALINOWSKI, B.

1985 [1922] Los argonautas del Pacífico Occidental, Barcelona, Península.

MARCUS, G. E.

1991

"Identidades passadas presentes e emergentes, requisitos para etnografias sobre a modernidade, no final do século XX, a nível mundial”, Revista de Antropologia, vol. 34, São Paulo, p. 197-221.

1994

"The modernist sensibility in recent ethnographic writing and the cinematic metaphor of montage", in DEVEREAUX, L \& HILLMAN, R. (eds.), Fields of vision, essays in film studies, visual anthropology, and photography, Berkeley and Los Angeles, University of California Press.

1995 "The modernist sensibility in recent ethnographic writing and the cinematic metaphor of montage", in DEVEREAUX, L. \& HILLMAN, R. (eds.). Fields of vision, essays in film studies, visual anthropology, and photography, Berkeley/ Los Angeles, University of California Press, p. 35-55.

MARCUS, G. \& FISCHER, M.

1986 Anthropology as cultural critique, Chicago, University of Chicago Press

MENDEZ, L.

La antropologia antes las artes plásticas, Madrid, CIS/Siglo XXI. 
MEUNIER, J.-P.

1994 "Image, cognition, centration, décentration", Cinémas, Revue d'Études Cinématographiques, 2, p. 27-47.

MIRZOEFF, N.

An introduction to visual culture, London, Routledge.

2003

Una introducción a la cultura visual, Barcelona, Paidós.

ODIN, R.

1995 Le film de famille, usage privé, usage public. Paris, Méridiens-Klincksiek.

PIAULT, M.-H.

$2000 \quad$ Antropologie et cinéma, Paris, Nathan Cinéma.

PINK, S.

1992 "Nouvelles perspectives après une Formation à L'Anthropologie Visuelle", Journal des Anthropologues, 47, 48, p. 123-37.

POSTMAN, N.

1998

Technopoly: the surrender of culture to technology, New York, Vintage Books.

RIBEIRO, J.

"Cem anos de imagens do mundo, panorama do cinema etnográfico francês", in Imagens do mundo, mostra do cinema etnográfico francês, Lisboa, CEAS/ ISCTE, CEMRI/UA e Serviço Cultural da Embaixada da França.

RIBEIRO, J. da S.

2001 Colá S. Jon, Oh que Sabe, as imagens, as palavras dotas e a escrita de uma experiência social e ritual, Porto, Afrontamento.

2003 Métodos e técnicas de investigação em antropologia, Lisboa, Universidade Aberta.

2004 Antropologia visual: da minúcia do olhar ao olhar distanciado, Porto, Afrontamento.

ROSENSTONE, R. A.

1997 El pasado en imágenes. El desafio del cine a nuestra idea de la Historia, Barcelona, Ariel. 
Revista de Antropologia, São Paulo, USP, 2005, v. 48 No 2.

SABOURAUD, F.

1999 "Enfin, la DV vint", in Limage, le monde, Liège, p. 56-63.

SOHAT, E. \& STAM, R.

2002 Multicultutalismo, cine y médios de comunicacion, Barcelona, Paidós.

SPERBER, D.

1989 "L'etude anthropologique des representations: problemes et perspectives", in JODELET, D. Les representations sociales, Paris, PUF.

STAM, R

2001

Teorias del cine, Barcelona, Paidós. 
ABSTRACT: The visual anthropology was Born in the mid-XIX century with the "age of technical reproduction" and the industrial expansion. How can one reformulates today, in the age of globalization and digital transformation, this discipline or disciplinary convergence? Having been initially focused on the documentation and preservation of endangered cultural practices, an anthropology of urgency, how it eventually mutated in visual, sound, audiovisual narrative forms, and, more recently, digital forms? Originally focused on feeding and enriching the museum's collections, how it is transmitted today by means of multiple forms and media to the public space in its search for new spectators/actors (or audiences)? First an instrumentation that apparently granted it an objective view, allocating to itself the status of research technology or even an assistant of research, how did it confronted or anticipated itself to new epistemological paradigms? Oriented above all for the recording of the ritual and material techniques and, after that, for words and sounds, how does it orients itself today in the scope of new objects of study as the anthropology of art, the anthropology of design, visual culture in contexts of accelerated social and cultural transformation processes? We add two more questions to the unrest that makes as reflect on this theme: how can one rethink today visual anthropology regarding anthropology per se? What it is one to do with visual anthropology today? We will seek to draw some ways of ancient practices that are gaining a new, better importance in this day and age (the work with archives, memory, the relation between past and project, the objects, the material culture) and put new opportunities, new practices, new objects of study into perspective.

KEY-WORDS: visual anthropology, age of technical reproduction, age of digital transformation, hypermedia, digital visual narratives.

Aceito em novembro de 2005. 